about forty bands, shaded towards the red. Some of these show rotation structure. The bands do not converge before $1850 \mathrm{~A}$. (154 kcal.); the heat of dissociation of $(\mathrm{CN})_{2}$ into $2 \mathrm{CN}$ must therefore be greater than $81 \mathrm{kcal}$., if the dissociation at the convergence limit leads to $\mathrm{CN}$ and $\mathrm{CN}^{\prime}$ (73 kcal.). The heat of dissociation calculated from thermochemical data is $66 \mathrm{kcal}$. The photo-dissociation may, however, produce vibrating CN molecules. This would account for the discrepancy. A full description of these absorption spectra will be published shortly.

R. B. MOONEY. H. G. REID.

Chemistry Department,

University of Edinburgh, July 23.

The Gritical Increment of the Adsorption of Hydrogen on Amorphous Garbon at $400^{\circ}-520^{\circ} \mathrm{C}$.

THE rates of adsorption of hydrogen on amorphous carbon have been measured for pressures ranging from $1 \mathrm{~cm}$. to $10^{-3} \mathrm{~cm}$. of mercury. Assuming that the rate of reaction is proportional to the pressure and to the surface covered, the rates will be given by the equation

$$
-d p / d t=k\left(A p+p^{2}\right)
$$

where $k$ is the velocity constant and $A$ is a constant containing the area. This equation holds for the whole range of pressures and temperatures investigated, but $A$ is not independent of temperature; it practically doubles as the temperature is increased from $400^{\circ}$ to $520^{\circ} \mathrm{C}$. The values of $\log k$ plotted against $1 / T$ give a straight line, and from the slope a critical increment of 30,000 cal. is calculated.

If the reaction be written,

$$
\text { (1) } 2 \mathrm{C}_{\mathrm{s}}+\mathrm{H}_{2}=2 \mathrm{C}-\mathrm{H} \text {, }
$$

and Mecke's values for the $\mathrm{C}-\mathrm{C}, \mathrm{C}-\mathrm{H}$, and $\mathrm{H}-\mathrm{H}$ linkings be adopted, namely, 65, 90, and 101 kcal., the reaction is exothermic to the extent of 14 kcal., and if the carbon surface be activated, the heat of reaction will be larger. It is doubtful if the reaction actually occurs in this way, for the adsorbed gas is evolved as hydrogen on evacuating under a high vacuum at $800^{\circ}-900^{\circ} \mathrm{C}$., whereas if the hydrogen had combined with the carbon, some methane would be expected. There is thus no evidence that the hydrogen has entered into chemical combination with the surface. It is possible, however, that the hydrogen molecules are dissociated into atoms by the process,

$$
\text { (2) } 2 \mathrm{C}-+\mathrm{H}_{2}=2 \mathrm{C}_{8}+2 \mathrm{H} \text {, }
$$

which is endothermic to the extent of 30-35 kcal. which corresponds with the observed critical increment. The result of the change is a deactivation of the surface with the production of adsorbed hydrogen atoms. On desorption, however, the surface returns to its original activity, so that if the above process occurs, it must be reversible.

The adsorption of hydrogen on carbon at $450^{\circ} \mathrm{C}$. resembles that found previously for the adsorption of hydrogen and carbon monoxide on $\mathrm{ZnO}-\mathrm{Cr}_{2} \mathrm{O}_{3}$ at room temperature, ${ }^{1}$ and for the adsorption of hydrogen on manganese dioxide at $400^{\circ} \mathrm{C} .{ }^{2}$ It is unlike that of oxygen on carbon at room temperatures, for in this case the oxygen can only be removed from the surface in combination with carbon, and it is different from that of hydrogen and carbon monoxide on $\mathrm{ZnO}-\mathrm{Cr}_{2} \mathrm{O}_{3}$ at $100^{\circ} \mathrm{C}$., for these gases remove oxygen atoms from the surface on desorption. The adsorption of hydrogen on carbon appears to be of a type intermediate between van der Waals' adsorption and true chemisorption.

The main difficulty in the acceptance of equation (2) lies in the fact that carbon monoxide also gives rise to the intermediate type on oxide catalysts, where dissociation into atoms is not possible.

F. E. T. KINGMAN.

Department of Physical Chemistry,

The University, Bristol.

1 Garner and Kingman, NATURE, Sept. 6, 1930 ; Far. Soc., 27, 322 ; 1931

H. S. Taylor and Williamson, J.A.C.S., 53, 2168 ; 1931.

\section{Intensity of Raman Scattering in Gases.}

UsING the apparatus described in earlier notes in NATURE, it has been found possible to estimate by photographic photometry the intensities of the Raman lines given by various simple gases and to make a quantitative test of the theory put forward by Manneback $^{1}$ The results, on the whole, seem to be favourable to the theory. The intensities of the rotational Raman lines representing the $0 \rightarrow 1,1 \rightarrow 3,2 \rightarrow 4$, and $3 \rightarrow 5$ quantum transitions in hydrogen gas are respectively in the ratio $1: 3: 0 \cdot 4: 0 \cdot 2$, Manneback's values being $1: 2 \cdot 8: 0 \cdot 35: 0 \cdot 19$. His theory further enables us to express the absolute intensities of these lines as fractions of the undisplaced Rayleigh lines if the optical anisotropy of the molecule is known. This may be computed from the observed depolarisation of the Rayleigh scattering. In the case of hydrogen, the calculated intensity of the $0 \rightarrow 2$ rotational line, the first of the above series, comes out as $3.5 \times 10^{-3}$, the observed value being $2 \times 10^{-3}$.

Manneback's expressions further show that while the Rayleigh scattering depends on the optical polarisability and anisotropy of the molecules, the vibrational Raman lines are connected with the variation of these quantities with varying nuclear distance. We have at present no experimental knowledge of the latter quantities, but following a method due to Ramanathan ${ }^{2}$ it is possible to estimate them theoretically and thus evaluate Manneback's formulæ numerically. In this way it is found that the intensity of the strongest line in the $Q$ branch of $\mathrm{H}_{2}(0 \rightarrow 1$ vib. $1 \rightarrow 1$ rot.) when expressed as a fraction of the Rayleigh line should be $1.63 \times 10^{-3}$, while the observed value is $1.5 \times 10^{-3}$. A qualitative agreement is also found with oxygen $\left(\mathrm{O}_{2}\right)$ and nitrogen $\left(\mathrm{N}_{2}\right)$. It may be noted that the existence of nearly unpolarised rotational Raman scattering with appreciable intensity necessitates a revision of the hitherto accepted values of the depolarisation of Rayleigh scattering, and this has been taken into account in the above computations.

210, Bowbazar Street, S. Bhagavantam.

Calcutta, India.

1 Zeit. für Phys., vol. 62, p. 224; 1930.

2 Proc. Roy. Soc., vol. 107 , p. $684 ; 1925$.

\section{Anomalous X-ray Diffraction Intensities.}

THE general explanation of the observations previously described under the above heading ${ }^{1}$ probably follows, as stated there, from the wellknown Laue equations connecting line-breadth with the size of a crystallite measured in a direction $a_{1}$. I have recently become aware of a paper by $R$. Brill, ${ }^{2}$ in which this aspect of Laue's work first appears to have been demonstrated quantitatively, and I would like to add this to my former note in order to direct attention to that paper. $\quad$ W. A. Wood. Physics Department,

The National Physical Laboratory,

Teddington, Middlesex, July 17.

1 NATURE, of May 9.

2 Zeit. für Krist., 75, 217.

No. 3224, VoL. 128] 